\title{
Printed Modular Distance Learning in Philippine Public Elementary Schools in Time of COVID-19 Pandemic: Quality, Implementation, and Challenges
}

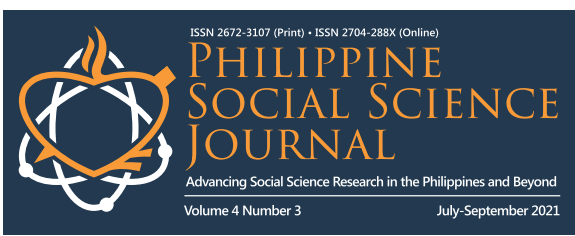

Allen Jake S. Talimodao ${ }^{1}$ and Dennis V. Madrigal ${ }^{2}$

${ }^{1}$ Asuncion L. Lizares Elementary School, Bacolod City, Philippines

${ }^{2}$ University of Negros Occidental-Recoletos, Bacolod City, Philippines

\section{Article history:}

Submitted: 23 July 2021

Revised: 13 October 2021

Accepted: 25 October 2021

\section{Keywords:}

Educational management

Printed modular distance Learning

Descriptive-comparative

Public elementary schools

Philippines

\begin{abstract}
Coronavirus Disease 2019 forced educational sectors worldwide to implement various distance learning modalities. In the Philippines, printed modular distance learning modality was implemented to continue delivering quality and relevant education amid the pandemic. Thus, this study assessed the quality and implementation of PMDL in public elementary schools. Likewise, this study ranked the challenges encountered by the teachers in the quality and implementation of PMDL. Using descriptive and inferential analyses, the results revealed that both quality and implementation of PMDL were consistently excellent, indicating the adherence of the modality to the national standards set by the Department of Education. However, significantly lower quality of PMDL among small and medium schools and the encountered challenges of teachers on assessments, activities, outputs, parents' incapacity, inconsistent participation, and compliance established the need for instructional supervision.
\end{abstract}

\subsection{Introduction}

The Coronavirus Disease 2019 (COVID-19) pandemic has posed significant challenges to educational sectors worldwide (Tria, 2020). Although many countries worldwide struggle to continue education during the pandemic, learning must continue (Dangle \& Sumaoang, 2020). Various distance learning modalities, such as modular distance learning, have been implemented in the United States of America and Australia (Valencia, 2020). In the compilation report of World Bank (2020), Asian countries like India and the Philippines also have implemented printed modular learning in education, which is thought to be effective (Sejpal, 2013) and favorable (Sadiq \& Zamir, 2014).

Modular learning is one of the most widespread and recognized teaching-learning techniques in the United States, Australia, and Asia. It effectively promotes reflective learning rather than focus on marks or grades (Sejpal, 2013). Also, Loughran and Russell (2004) and Ali et al. (2010) have proven in their studies that modular learning in basic education is a more effective mode of instruction than the traditional teaching method because it allows individuals to learn more at their own pace. Similarly, Karthikeyan and Kumar (2014) found that students generally favored modular learning as a more interesting and useful learning experience than conventional learning in their dermatology class. Finally, Sadiq and Zamir (2014) concluded that modular learning is favorable and should be widely used at various education levels.

In the Philippines, printed modular distance learning is extensively used by the Department of Education (DepEd) as one of the Alternative Delivery Modes (ADM). Though printed modular distance learning gained skepticism, Guido (2014) concluded that it is effective for the knowledge adaptation of science and engineering students. Nardo (2017) also found that modular learning develops a sense of responsibility among students, enhancing learner autonomy. Lastly, Valencia (2020), in her study on modular learning in basic education, found that the academic performance of learners improved due to modular learning.

Studies have been conducted on the nature of modular learning globally (Parlakkilic, 2015; Dejene, 2019) and in the Philippines (Zulueta \& Guimbatan, 2002; Unay et al., 2016). Other studies also have identified the effects of modular learning on the learning process (Cornford, 1997; Matanluk et al., 2013; Cabrera, 2014; Lim, 2016) and student performance (Chua et al., 2007; Bedaure, 2012). To 
date, however, there is a dearth of substantial literature assessing the quality and implementation of printed modular distance learning. For such reason, Goode (2003), Guido (2014), and Nardo (2017) recommended that teachers conduct relative researches on modular learning following the national standards in order to achieve a caliber educational perspective.

This study aimed to describe the level of quality and extent of implementation of PMDL as assessed by the teachers in public elementary schools at a schools division in a highly urbanized city in Central Philippines in the school year 2020-2021. Likewise, it aimed to identify the challenges encountered by the teachers in the quality and implementation of PMDL. The findings of the study were used as the basis for the Development of the Instructional Supervision Monitoring Tool, which teachers could use to comply with the established principles and standard operating procedures in the quality and implementation of PMDL.

\subsection{Framework of the Study}

This paper theorized that the assessment of the quality and implementation of PMDL varies according to the teachers' perception as anchored on instructional theory and theory of individualizing instruction. The instructional theory states that the instructional strategies of a teacher such as PMDL (Nwagbara \& Ezekwe, 2015) depend on whom and what they are trying to teach and where (Wilson \& Peterson, 2006). Similarly, the theory of individualizing instruction originally assumes that no two living organisms are alike, as perceived by Wang (2013). In addition, individualizing instruction through PMDL is the opposite of one-size-fits-all, whereby a teacher suits the instruction based on his or her style and according to the learner's needs, interests, and individual characteristics (Russo, 2002).

In particular, Rivkin et al. (2005) undermine this assumption. They found that even when there is some evidence that a master's degree or higher improves the overall quality of PMDL, all estimates are statistically insignificant. Similarly, French (2015) found that time and place are not a factor in modular learning because flexibility allows learners to study according to their own pace and selfregulation (Lim, 2016). Nevertheless, the assumption of the study is seconded by Lee and Loeb (2020). They concluded that teachers in smaller schools are more likely to take more responsibility for their students' learning than in larger schools. Weiss et al. (2010) similarly stated that moderately sized schools have the greatest engagement advantage in which engagement is necessary for any teaching method. Thus, this study responds to Goode (2003), Guido (2014), and Nardo (2017), who recommended that teachers conduct relative researches on modular learning.

\subsection{Methods}

This study employed the descriptive-comparative research design, which determined the level of quality and extent of the implementation of printed modular distance learning in a schools division in a highly urbanized city in Central Philippines during the school year 2020-2021 as assessed by the teachers as a whole and when grouped according to highest educational attainment, school location, and school category. Table 1 shows the profile of the respondents.

Selected through random sampling, the 377 public elementary school teachers answered an electronically generated instrument with three parts: the profile of the respondents, the 57 -item questionnaire, which assessed the quality and implementation of PMDL, and the checklist on the challenges encountered by the teachers. The indicators in the research instrument were based on the ALS-EST Handbook for Implementers, DepEd Memorandum Order 1 series of 2021, and the Nonnegotiable Minimum Requirements for Distance Learning Modalities. In interpreting the data, both the quality and implementation of PMDL used the scale: 1-Very Poor, 2-Poor, 3-Good, 4-Excellent. Most importantly, the researcher addressed the general ethical principles of respect for persons, beneficence, and justice to ensure the ethical soundness of the study.

In analyzing the data, Mean and Standard Deviation were used to determine the level of quality and extent of implementation of PMDL. Meanwhile, Frequency Count, Percentage Distribution, and Rank were employed to identify the challenges on the two variables. Further, Mann-Whitney $U$ Test and Kruskal Wallis compared the difference in the quality and implementation of PMDL when grouped according to the highest educational attainment, school location, and school category. 
Table 1. Profile of the Respondents

\begin{tabular}{lcc}
\hline Variable & f & \% \\
\hline Highest Educational Attainment & & \\
$\quad$ Bachelor's Degree & 277 & 73.5 \\
Master's Degree & 96 & 25.5 \\
$\quad$ Doctorate Degree & 4 & 1.1 \\
School Location & & \\
$\quad$ Rural & 61 & 16.2 \\
$\quad$ Urban & 316 & 83.8 \\
School Category & & \\
Medium & 87 & 23.1 \\
Large & 109 & 28.9 \\
Mega & 181 & 48.0 \\
Total & $\mathbf{3 7 7}$ & $\mathbf{1 0 0 . 0}$ \\
\hline
\end{tabular}

\subsection{Results and Discussion}

\section{Level of quality of printed modular distance learning}

Generally, the findings in Table 2 showed that the level of quality of printed modular distance learning is excellent $(M=3.33, S D=0.40)$. This implies that the teachers perceive $P M D L$ to excellently adhere to the principles set by DepEd. Significantly, the rest of the population subgroups also yielded an "excellent" level of quality. Particularly, teachers with a doctorate degree $(M=3.36, S D=0.40)$, teaching in urban $(M=3.34, S D=0.41)$ and large schools $(M=3.42, S D=0.44)$ have the highest perceptions of quality of PMDL compared to their counterparts. Thus, they may serve as models on how they ensured and evaluated the quality of PMDL. On the other hand, teachers with bachelor's $(M=3.33, S D=0.40)$ and master's degrees $(M=3.33, S D=0.46)$, teaching in rural schools $(M=3.30$, $\mathrm{SD}=0.42)$ and medium schools $(\mathrm{M}=3.18, \mathrm{SD}=0.38)$ perceived lower quality of PMDL. Hence, they may be provided with instructional supervision to ensure that the quality of PMDL is not compromised in their respective contexts.

Table 2. Level of Quality of Printed Modular Distance Learning

\begin{tabular}{lccc}
\hline Variable & $\mathrm{M}$ & $\mathrm{SD}$ & Interpretation \\
\hline $\begin{array}{l}\text { Highest Educational Attainment } \\
\text { Bachelor's Degree }\end{array}$ & 3.33 & 0.40 & Excellent \\
$\quad$ Master's Degree & 3.33 & 0.46 & Excellent \\
$\quad$ Doctorate Degree & 3.36 & 0.21 & Excellent \\
$\begin{array}{l}\text { School Location } \\
\quad \text { Rural }\end{array}$ & 3.30 & 0.42 & Excellent \\
$\quad$ Urban & 3.34 & 0.41 & Excellent \\
School Category & & & \\
$\quad$ Medium & 3.18 & 0.38 & Excellent \\
$\quad$ Large & 3.42 & 0.44 & Excellent \\
$\quad$ Mega & 3.35 & 0.39 & Excellent \\
As a Whole & 3.33 & 0.41 & Excellent \\
\hline
\end{tabular}

The results indicate that DepEd successfully standardized the quality of PMDL. On recommendations made by Delgado and Villaganas (2015), Camara (2016), and Ambayon and 
Millenes (2020) to evaluate the quality of PMDL, the findings substantiated that PMDL is aligned to the level of the learners (Lim, 2016). It is logically planned, developed, organized, and validated in terms of layout and content (Torrefranca, 2017), self-instructional (Macarandang, 2009), gender and culture-sensitive (Bedaure, 2012), promoted reflective thinking (Nardo, 2017), and enhanced higher-order thinking skills such as analyzing, problem-solving, and self-regulating (Paspasan, 2015). These findings significantly establish that the quality of PMDL is adherent to the national standards of DepEd and may provide the basis to continue using the modality. Nevertheless, the lower quality of PMDL in some teacher demographics suggests that the modality can still be further improved through instructional supervision.

\section{Extent of implementation of printed modular distance learning}

Generally, the findings in Table 3 showed that the extent of implementation of printed modular distance learning is excellent $(M=3.59, S D=0.36)$. Consequently, the results primarily indicate that DepEd is successful in standardizing the implementation of PMDL. The results further showed that the extent of implementation of all subgroups under highest educational attainment, school location, and school category is also "excellent." Particularly, teachers with a doctorate degree $(M=3.66$, $S D=0.46)$ and teaching in rural $(M=3.64, S D=0.36)$ and large schools $(M=3.63, S D=0.36)$ have the highest perceptions of the implementation of PMDL compared to their counterparts. Hence, they may serve as models on how they implemented and evaluated the said modality.

Table 3. Extent of Implementation of Printed Modular Distance Learning

\begin{tabular}{lccc}
\hline Variable & $\mathrm{M}$ & $\mathrm{SD}$ & Interpretation \\
\hline Highest Educational Attainment & & & \\
$\quad$ Bachelor's Degree & 3.59 & 0.36 & Always \\
$\quad$ Master's Degree & 3.54 & 0.38 & Always \\
$\quad$ Doctorate Degree & 3.66 & 0.46 & Always \\
$\begin{array}{l}\text { School Location } \\
\quad \text { Rural }\end{array}$ & 3.64 & 0.36 & Always \\
$\quad$ Urban & 3.57 & 0.36 & Always \\
School Category & & & \\
$\quad$ Medium & 3.52 & 0.40 & Always \\
$\quad$ Large & 3.63 & 0.36 & Always \\
$\quad$ Mega & 3.57 & 0.35 & Always \\
As a Whole & 3.58 & 0.36 & Always \\
\hline
\end{tabular}

Likewise, teachers with master's degrees $(M=3.54, S=0.38)$ and teaching in urban $(M=3.57$, $\mathrm{S}=0.36)$ and medium schools $(\mathrm{M}=3.52, \mathrm{SD}=0.40)$ imply that some inconsistencies must be minimized if not eliminated in their contexts through adequate instructional supervision.

Relatedly, as mentioned earlier that quality must be assured before implementation (Sewagegn \& Diale, 2021), findings prove that adequate planning and preparation, as success determinants of a program (Magulod, 2017), were conducted before the actual implementation of PMDL. Likewise, the findings reveal that teachers took active roles in implementing PMDL, stakeholders were properly informed on their responsibility to monitor learner progress (Guido, 2014), learners received timely and relevant feedbacks, and parents shared the responsibility in the implementation of PMDL (Dangle \& Sumaoang, 2020). Succinctly, the collaboration among stakeholders was evident, enabling the excellent implementation of PMDL (Olamo et al., 2019). Noting on the recommendation of Macarandang (2009) that teachers use PMDL in face-to-face instruction, the findings imply that PMDL may both be beneficial as a distance learning modality and a supplementary modality to faceto-face learning.

\section{Difference in the level of quality of printed modular distance learning when grouped according to highest educational attainment and school category}

As seen in Table 4, there is no significant difference in the level of quality of printed modular 
distance learning when the teachers are grouped according to educational attainment $[\chi 2(2)=0.117$, $\mathrm{p}=0.943]$. Hence, there are insufficient data to reject the null hypothesis. Also, the working theory that the quality of PMDL varies according to the demographics of the teacher, such as highest educational attainment, is debunked.

This indicates that the quality of PMDL is consistently excellent regardless of the educational attainment of teachers. Though teachers with bachelor's and master's degrees perceived lower quality of $\mathrm{PMDL}$, the findings proved that they were able to ensure the quality of PMDL in their local contexts. Nevertheless, instructional supervision is needed to maintain the quality of PMDL regardless of the highest educational attainment of teachers.

Elaborately, the results on the quality of PMDL when teachers are grouped according to their highest educational attainment strengthen the findings of Rivkin et al. (2005), which demonstrated that even when there is some evidence that a master's degree or higher improves the overall quality of teaching as in PMDL, all estimates are statistically insignificant. Also, Buddin and Zamarro (2009) found that teachers with master's or doctorate degrees are not better or worse than comparable teachers without advanced degrees. Moreover, the findings discredit the findings of Zhang (2008) and Greenberg et al. (2004) that teachers with master's degrees or doctorate degrees provide better instruction.

In addition, the findings of the study debunk its working theory that the quality of PMDL varies according to the demographics of the teacher. The assumption of the instructional theory that PMDL varies according to the instructional strategies (Wilson \& Peterson, 2006) is no longer valid. Similarly, the findings of Zhang (2008) regarding instructional strategy being influenced by the educational attainment of a teacher are therefore discredited. On the other hand, this boosts the findings of Rivkin et al. (2005) that the quality of PMDL as one of the instructional methods has no difference in terms of teachers' educational attainment. Thus, the findings imply that regardless of teachers' educational attainment, the quality of PMDL is excellent.

Meanwhile, there is a significant difference in the level of quality of printed modular distance learning when the teachers are grouped according to school category $[\chi 2(2)=16.653, p=0.000]$. The Post hoc test revealed that teachers from small and medium schools rated significantly lower than other teachers. Hence, there are sufficient data to reject the null hypothesis. Also, the working theory that the quality of PMDL varies according to the demographics of the teacher, such as school category, is proven.

This indicates the inconsistent quality of PMDL among teachers in small, medium, mega, and large schools. Thus, teachers in small and medium schools perceive a lower quality of PMDL than their counterparts, suggesting that instructional supervision must be in place to ensure that the quality of PMDL is not compromised in their contexts. Nevertheless, teachers from large and mega schools may provide a benchmark to their counterparts to showcase how they ensured and evaluated

Table 4. Difference in Level of Quality of Printed Modular Distance Learning according to Highest Educational Attainment and School Category

\begin{tabular}{ccccccc}
\hline \multirow{3}{*}{ Variable } & \multicolumn{2}{c}{ Highest Educational Attainment } & $\chi^{2}$ & $\mathrm{df}$ & $\mathrm{p}$ \\
\cline { 2 - 7 } & $\begin{array}{c}\text { Bachelor's } \\
\text { Degree }\end{array}$ & $\begin{array}{c}\text { Master's } \\
\text { Degree }\end{array}$ & $\begin{array}{c}\text { Doctorate } \\
\text { Degree }\end{array}$ & & & \\
\hline \multirow{5}{*}{ Quality } & 3.33 & 3.33 & 3.36 & 0.117 & 2 & 0.943 \\
& $(0.02)$ & $(0.05)$ & $(0.10)$ & & & \\
\cline { 2 - 7 } & \multicolumn{7}{c}{ School Category } & & $\chi^{2}$ & $\mathrm{df}$ & $\mathrm{p}$ \\
\cline { 2 - 7 } & Small and & Large & Mega & & & \\
& Medium & $3.12_{\mathrm{a}}$ & $3.35_{\mathrm{b}}$ & $16.653^{*}$ & 2 & 0.000 \\
& $(0.04)$ & $(0.04)$ & $(0.03)$ & & & \\
\hline
\end{tabular}

Note: *the difference is significant when $\mathrm{p} \leq 0.05$

the quality of PMDL.

Furthermore, the results on the quality of PMDL when teachers are grouped according to school 
category strengthen the conclusion of Howley et al. (2000), stating that school category affects teacher instruction. Leithwood and Jantzi (2009) also affirmed that school size affects various student and organizational outcomes. In Weiss et al. (2010) longitudinal study, moderately sized schools have the greatest engagement advantage in which engagement is necessary for any teaching instruction. Noting that PMDL significantly improves academic performance (Chua et al., 2007) and academic success (Cacayan et al., 2017), the quality of PMDL should be reviewed in small and medium schools in terms of performance standards, format, and content which should address what the learners truly need (Delgado \& Villaganas, 2015).

\section{Difference in the level of quality of printed modular distance learning when grouped according to school location}

As seen in Table 5, there is no significant difference in the level of quality of printed modular distance learning when the teachers are grouped according to school location $[U=8986.00, p=0.402]$. Hence, there are insufficient data to reject the null hypothesis. Also, the working theory that the quality of PMDL varies according to the demographics of the teacher, such as school location, is debunked.

This indicates that the quality of PMDL is excellent regardless of the school location. This generally implies that the quality of PMDL across urban and rural schools is excellent primarily because of flexibility in learning. This also assures that regardless of the school location, the same quality of learning through PMDL is received by the learners.

Relatedly, flexibility and self-regulation are the major qualities of the PMDL (Lim, 2016). French (2015) also added that time and place are not a factor in modular learning because of flexibility in learning through PMDL. The findings are in congruence with the study of Nnamani and Oyibe (2016), which states that the quality of an instructional method such as modular learning depends on the location of the school. Moreover, the findings of the study debunk the instructional theory whereby the quality of PMDL is not differed by the school location.

Notably, both rural and urban schools provide a quality flexible learning environment to learners (Ambayon \& Millenes, 2020). This proves that the quality of PMDL is excellent in providing mass education and individualized instruction (Aquino et al., 2011). Succinctly, the findings hereby fulfill the recommendation of Nwagbara and Ezekwe (2015) that modular learning is applied and evaluated in terms of quality (Macarandang, 2009; Ambayon \& Millenes, 2020) in rural areas to determine whether a school location is a factor in modular learning.

Table 5. Difference in Level of Quality of Printed Modular Distance Learning according to School Location

\begin{tabular}{|c|c|c|c|c|c|}
\hline \multirow{2}{*}{ Variable } & \multicolumn{2}{|c|}{ School Location } & \multirow{2}{*}{ U } & \multirow{2}{*}{$z$} & \multirow{2}{*}{$\mathrm{p}$} \\
\hline & Rural & Urban & & & \\
\hline Quality & $\begin{array}{c}3.30 \\
(0.42)\end{array}$ & $\begin{array}{c}3.34 \\
(0.41)\end{array}$ & 8986.000 & -0.837 & 0.402 \\
\hline
\end{tabular}

Note: *the difference is significant when $\mathrm{p} \leq 0.05$

\section{Difference in the extent of implementation of printed modular distance learning when grouped according to highest educational attainment and school category}

The findings in Table 6 indicate that there is no significant difference in the extent of implementation of printed modular distance learning when the teachers are grouped according to educational attainment $[\times 2(2)=1.146, p=0.564]$ and school category $[\chi 2(2)=3.959, p=0.138]$. Hence, there are insufficient data to reject the null hypothesis. Also, the working theory that the implementation of PMDL varies according to the demographics of the teacher, such as highest educational attainment and school category, is debunked.

The findings show that teachers, regardless of their educational attainment, took active roles in the planning, implementing, and monitoring of learner performance. The findings likewise denote that regardless of the highest educational attainment of teachers, they are all equally committed to standardizing the implementation of PMDL in their contexts. Meanwhile, in terms of school category, the findings mean that PMDL was standardized regardless of the number of teachers. This indicates that teachers share equal duties and responsibilities in implementing PMDL. 
Table 6. Difference in Extent of Implementationof Printed Modular Distance Learning according to Highest Educational Attainment and School Category

\begin{tabular}{ccccccc}
\hline \multirow{3}{*}{ Variable } & \multicolumn{2}{c}{ Highest Educational Attainment } & $\chi^{2}$ & $\mathrm{df}$ & $\mathrm{p}$ \\
\cline { 2 - 7 } & $\begin{array}{c}\text { Bachelor's } \\
\text { Degree }\end{array}$ & $\begin{array}{c}\text { Master's } \\
\text { Degree }\end{array}$ & $\begin{array}{c}\text { Doctorate } \\
\text { Degree }\end{array}$ & & & \\
\hline \multirow{5}{*}{ Extent } & 3.59 & 3.54 & 3.66 & 1.146 & 2 & 0.564 \\
& $(0.02)$ & $(0.04)$ & $(0.23)$ & & & \\
\cline { 2 - 7 } & \multicolumn{7}{c}{ School Category } & $\chi^{2}$ & $\mathrm{df}$ & $\mathrm{p}$ \\
\cline { 2 - 7 } & $\begin{array}{c}\text { Small and } \\
\text { Medium }\end{array}$ & Large & Mega & & & \\
& 3.52 & 3.63 & 3.57 & 3.959 & 2 & 0.138 \\
& $(0.04)$ & $(0.03)$ & $(0.03)$ & & & \\
\hline
\end{tabular}

Note: *the difference is significant when $\mathrm{p} \leq 0.05$

The findings support Buddin and Zamarro (2009), noting that teachers with master's or doctorate degrees are not better or worse in their instruction than comparable teachers without advanced degrees. However, the findings rebuke the conclusion that a larger school size means more economic efficiency, especially in producing learning materials, but it becomes a deterrent in academic outcomes (Ready et al., 2004). Another conclusion debunked by the findings is that teachers in smaller schools are more likely to take more responsibility for their students' learning than in larger schools (Lee \& Loeb, 2020). Their notion that elementary schools must be limited in size so that the benefits that individual pupil receives in policies implemented are maximized is not evident based on the findings of the study.

\section{Difference in the extent of implementation of printed modular distance learning when grouped according to school location}

The findings in Table 7 indicate no significant difference in the extent of implementation of printed modular distance learning when the teachers are grouped according to school location $[\mathrm{U}=8404.50, p=0.112]$. Hence, there are insufficient data to reject the null hypothesis. Also, the working theory that the implementation of PMDL varies according to the demographics of the teacher, such as school location, is debunked. This indicates that the quality of PMDL is consistently excellent among rural and urban schools.

Generally, the findings denote that the excellent adherence to national standards in the implementation of PMDL is consistent with all rural and urban schools. Since rural and urban schools use the same quality evaluated $\mathrm{PMDL}$, its consistent implementation strengthens the total quality of education learners receive regardless of their school location. This implies that PMDL transcends geographic distance whereby the standard of implementation by rural schools is the same as that of urban schools and vice versa. The teachers also, regardless of their school location, are properly informed and take active roles in the learning process of their learners. This goes to show the commitment among teachers in adhering to the national standards in implementing PDML.

Table 7. Difference in Extent of Implementation of Printed Modular Distance Learning according to School Location

\begin{tabular}{|c|c|c|c|c|c|}
\hline \multirow{2}{*}{ Variable } & \multicolumn{2}{|c|}{ School Location } & \multirow{2}{*}{ U } & \multirow{2}{*}{$z$} & \multirow{2}{*}{$\mathrm{p}$} \\
\hline & Rural & Urban & & & \\
\hline Extent & $\begin{array}{c}3.64 \\
(0.36)\end{array}$ & $\begin{array}{c}3.57 \\
(0.36)\end{array}$ & 8404.500 & -1.588 & 0.112 \\
\hline
\end{tabular}

Note: *the difference is significant when $p \leq 0.05$

The findings eliminate the disparity of quality of learning among rural and urban schools, disproving the conclusion of Sewagegn and Diale (2021), noting that even when the curriculum 
is harmonized at a national level, there are variations in implementing the modular approach. Also, PMDL made learning more accessible to learners debunking the conclusion that school location has also led to mass failure and dropout of students because of long walks with empty stomachs abandoning their educational and life goals (Mhiliwa, 2015). The findings respond to the recommendation of Nwagbara and Ezekwe (2015) that modular learning is implemented in rural areas to determine whether a school location is a factor in modular learning.

\section{Challenges in the quality and implementation of printed modular distance learning}

As shown in Table 8, teachers encountered major challenges in the quality of PMDL on the provision of summative assessment $50.9 \%(\mathrm{f}=192)$, appropriateness of activities/required outputs $47.7 \%(f=180)$, and availability of post-test provided in every module/lesson $47.2 \%(178)$. Moreover, the teachers encountered major challenges in the implementation of PMDL on parents' capacity of facilitating learning to children $72.4 \%(f=273)$, parent's participation in following up their children's progress $71.4 \%(269)$, and compliance by parents in getting and returning the self-learning modules $70.8 \%$ (267). However, teachers encountered no challenge in clarifying instructions of activities in the self-learning modules for quality and assignment of personnel to print in implementation of PMDL.

Overall, the major challenges in the quality of PMDL imply that teachers encountered the inadequacy and lack in the appropriateness of summative tests, activities, outputs, and post-tests given to the learners. This may have a detrimental effect on the quality of the modality, knowing that these factors must sufficiently provide learners with independent practice and self-regulation. Lastly, this also poses a challenge for module writers and the quality assurance team to redefine standards in publishing SLMs with adequate summative tests, activities, outputs, and post-tests. Nevertheless, teachers having no challenge in the clarity of instructions in SLMs indicates that simple language and easy-to-follow instructions are provided for the learners.

Meanwhile, teachers encountered parents' incapacity, inconsistent participation, and compliance as the major challenges in implementing PMDL. This implies that teachers recognize the significance of parental involvement to the academic success of learners. In addition, this greatly affects the academic progress of the learners, knowing that parents or guardians serve as learning facilitators who not only co-supervise and co-monitor pupils but also receive and return SLMs to schools. Such inconsistent participation and compliance delay the learners' accomplishment, which may have an adverse effect on the flexibility of learning through PMDL.

Table 8. Challenges in the Quality and Implementation of Printed Modular Distance

\begin{tabular}{lll}
\hline Challenges & $\mathrm{f}$ & $\%$ \\
\hline Quality of PMDL & & \\
Provision of a summative test by learning area & 192 & 50.9 \\
Appropriateness of activity/required output & 180 & 47.7 \\
Availability of post-test in every module/lesson & 178 & 47.2 \\
Accuracy to the approved MELC & 156 & 41.4 \\
Accuracy of content/lesson & 150 & 39.8 \\
\hline Implementation of PMDL & & \\
Parents' capacity of facilitating learning to children & 273 & 72.4 \\
Parent's participation in following up their children's progress & 269 & 71.4 \\
Compliance by parents in getting and returning the SLMs & 267 & 70.8 \\
Availability of printing supplies/materials & 248 & 65.8 \\
Accessibility of learning materials on the Website/Portals & 221 & 58.6 \\
Availability of functional facility/equipment & 220 & 58.4 \\
Completeness of SLMs distributed/retrieved & 190 & 50.4 \\
Quality of printing outputs & 189 & 50.1 \\
Participation of parents/LGU, etc. & 175 & 46.4 \\
Availability of schedule for distribution/retrieval & 172 & 45.6 \\
Reporting of learners' progress to parents & 153 & 40.6 \\
Feedback mechanism & 143 & 37.9 \\
Organization/System for distribution/retrieval & 128 & 34.0 \\
\hline
\end{tabular}


On the other hand, teachers perceive no challenge in the personnel assigned to print, which means persons responsible for printing are in place. Relatedly, the challenges above validated the challenges in implementing PMDL identified by Dangle and Sumaoang (2020). The need to address the challenge in the quality of PMDL, noting that self-learning activities and relevant assessments must be adequately provided for pupils to reflect on their own learning progress.

\subsection{Conclusion}

The Printed Modular Distance Learning Modality provides learners with equitable access to quality and relevant education during the COVID-19 pandemic. Meanwhile, significantly lower quality of PMDL in small and medium schools than their big and mega school counterparts signifies the need for instructional supervision to maintain excellent quality and address the current shortcomings. Nevertheless, the teachers affirm that in their demographics, such as highest educational attainment and local contexts, such as school category and school location, the department successfully standardizes the quality and implementation of PMDL.

Similarly, the challenges encountered by the teachers in the quality and implementation of PMDL suggest that teachers need support in the said modality. This is best addressed through instructional supervision. They can also receive adequate professional assistance so that challenges are addressed, and standardized quality and implementation of PMDL are sustained. Therefore, PMDL is advantageous to be re-implemented in the succeeding school years as a distance learning modality and even as a supplementary modality to face-to-face learning as in Modified In-School Off-School Approach (MISOSA).

It is recommended, therefore, that school administrators should employ adequate instructional supervision to maintain the excellent quality and implementation of PMDL and address the challenges encountered by the teachers. In the same manner, teachers may undergo training in writing thematic assessments to address better the challenges they encountered in the quality of PMDL. They may likewise conduct intervention programs to encourage parent participation and compliance, addressing their challenge in implementing PMDL. Lastly, they may undergo intensive training on utilizing modules in classroom teaching so that PMDL may be used as a supplementary learning modality to face-to-face instruction as the need requires. Future researchers are encouraged to conduct more studies on the quality and implementation of PMDL and explore other variables to validate the claims of this study.

\section{REFERENCES}

Ali, R., Ghazi, S. R., Khan, M. S., Hussain, S., \& Faitma, Z. T. (2010). Effectiveness of modular teaching in biology at the secondary level. Asian Social Science, 6(9). https://doi.org/10.5539/ass.v6n9p49

Ambayon, E. E., \& Millenes, C. (2020). Modular-based approach and students' achievement in literature. Available at SSRN 3723644. http://dx.doi.org/10.2139/ssrn.3723644

Aquino, R., Hagos, L., Evangelista, Y., Lim, U., \& Reyes, F. (2011). Effectiveness of the modular instructional material in the basic integration formulas in integral calculus. 3rd International Conference of Teaching and Learning (ICTL 2011), Malaysia.

Bedaure, A. (2012). Modular instruction in biology: Its effect on students' performance. JPAIR Multidisciplinary Research, 9(1). https://doi.org/10.7719/jpair.v9i1.2

Buddin, R., \& Zamarro, G. (2009). Teacher qualifications and student achievement in urban elementary schools. Journal of Urban Economics, 66(2), 103-115. https://doi.org/10.1016/j.jue.2009.05.001

Cabrera, F. (2014). Modular cooperative learning: A designed mathematics instruction for 21st-century education. UNP Research Journal, 23(1). https://ejournals.ph/article.php?id=11646

Cacayan, R., Tenorio, J., Romiro G. Bautista, R. (2017). Students' awareness of m-learning in the classroom pedagogical environment. QSU-CTE Journal of Education Practices and Standards, 2(1). http://ejournals.ph/ form/cite.php?id=11820

Camara, J. (2016). View of a validated module in biological science for college students in the Philippines. Southeast Asian Journal of Science and Technology. https://sajst.org/online/index.php/sajst/article/ view/49/45

Chua, O., Jacinto, E., \& Santos, V. (2007). Effectiveness of a module in the teaching of selected topics in engineering physics I, 4(1). https://ejournals.ph/article.php?id=9037

Cornford, I. (1997). Ensuring effective learning from modular courses: A Cognitive. Journal of Vocational Education \& Training, 49(2), pp.237-251. https://doi.org/10.1080/13636829700200014 
Dangle, Y. R. P., \& Sumaoang, J. D. (2020). The implementation of modular distance learning in the Philippine secondary public schools. In 3rd International Conference on Advanced Research in Teaching and Education (November 27-29), Dublin, Ireland. https://www. dpublication. com/wp-content/uploads/2020/11/27-427. pdf.

Dejene, W. (2019). The practice of modularized curriculum in higher education institution: Active learning and continuous assessment in focus. Cogent Education, 6(1), Research-Article. https://doi.org/10.1080/233118 6X.2019.1611052

Delgado, J. V. A., \& Villaganas, V. D. (2015). The effects of eclectic teaching approach in mathematics for grade IX students. Journal of Agriculture and Technology Management, 10-10. https://doi.org/10.29121/ granthaalayah.v5.i5.2017.1861

French, S. (2015). The benefits and challenges of modular higher education curricula. Issues and Ideas Paper. Melbourne: Melbourne Centre for the Study of Higher Education.

Goode, C. (2003). Evaluating the quality, usability, and potential effectiveness of online learning modules: A case study of teaching with technology grant recipients at the University of Tennessee, Knoxville. https://trace. tennessee.edu/cgi/viewcontent.cgi?article $=5983 \&$ context $=$ utk_graddiss

Greenberg, E., Rhodes, D., Ye, X., \& Stancavage, F. (2004, April). Prepared to teach: Teacher preparation and student achievement in eighth-grade mathematics. American Institute for Research, 2004 Annual Meeting, San Diego, CA.

Guido, R. M. D. (2014). Evaluation of a modular teaching approach in materials science and engineering. American Journal of Educational Research, 2(11), 1126-1130. https://doi.org/10.12691/education-2-11-20

Howley, C., Strange, M., \& Bickel, R. (2000). Research about school size and school performance in impoverished communities. Clearinghouse on Rural Education and Small Schools, Appalachia Educational Laboratory.

Kapfer, P., \& Swenson, G. (2015) Individualizing Instruction for Self-Paced Learning, The Clearing House: A Journal of Educational Strategies, Issues, and Ideas, 42:7, 405-410, DOI: 10.1080/00098655.1968.1147752

Karthikeyan, K., \& Kumar, A. (2014). Integrated modular teaching in dermatology for undergraduate students: a novel approach. Indian Dermatology Online Journal, 5(3), 266. https://doi.org/10.4103/2229-5178.137774

Lee, V. E., \& Loeb, S. (2000). School size in Chicago elementary schools: effects on teachers' attitudes and students' achievement. American Educational Research Journal, 37(1), 3-31. https://doi. org/10.3102/00028312037001003

Leithwood, K. \& Jantzi, D. (2009). A review of empirical evidence about school size effects: A policy perspective. Review of Educational Research, 79(1), 464-490. https://doi.org/10.3102/0034654308326158

Lim, E. J. (2016). Effectiveness of modular instruction in word problem solving of BEED students. IOSR Journal of Mathematics (IOSR-JM), 12(5), 59-65.

Loughran, J., \& Russell, T. (2004). Improving teacher education practice through self-study. Routledge.

Macarandang, M. (2009). Evaluation of a Proposed Set of Modules in Principles and Methods of Teaching. E-International Scientific Research Journal.

Magulod Jr, G. C. (2017). Factors of school effectiveness and performance of selected public and private elementary schools: implications on educational planning in the Philippines. Asia Pacific Journal of Multidisciplinary Research, 5(1), 73-83.

Matanluk, O., Mohammad, B., Kiflee, D. N. A., \& Imbug, M. (2013). The effectiveness of using teaching modules based on radical constructivism toward students learning process. Procedia-Social and Behavioral Sciences, 90, 607-615. https://doi.org/10.1016/j.sbspro.2013.07.132

Mhiliwa, J. A. (2015). The effects of school distance on students' academic performance: A case of community secondary schools in Makambako Town Council (Doctoral dissertation, The Open University of Tanzania).

Nardo, M. T. B. (2017). Modular instruction enhances learner autonomy. American Journal of Educational Research, 5(10), 1024-1034.

Nnamani, S. C., \& Oyibe, O. A. (2016). Effects of individualized instructional method on secondary school students' achievement in social studies. British Journal of Education, 4(3), 110-120.

Nwagbara, A., \& Ezekwe, E. (2015) Creativity and innovation in modular instruction of college mathematics: A key to the 21st-century transformation of the global economy. ASPROAEDU, Volume 1 No. 1.

Olamo, T. G., Mengistu, Y. B., \& Dory, Y. A. (2019). Challenges hindering the effective implementation of the harmonized modular curriculum: The case of three public universities in Ethiopia. Creative Education, 10(7), 1365-1382. https://doi.org/10.4236/ce.2019.107102

Parlakkilic, A. (2015). Modular Rapid E-Learning Framework (MORELF) in desktop virtualization environment: An effective hybrid implementation in nurse education. Turkish Online Journal of Distance Education, 16(1). https://doi.org/10.17718/tojde.21716

Paspasan, R. (2015). Structured approach vs. self-paced modular approach in teaching trigonometry. Asia Pacific Journal of Multidisciplinary Research, 3(5), 51-58.

Ready, D., Lee, V., \& Welner, K. G. (2004). Educational equity and school structure: School size, overcrowding, and schools-within-schools.

Rivkin, S. G., Hanushek, E. A., \& Kain, J. F. (2005). Teachers, schools, and academic achievement. Econometrica, 73(2), 417-458. https://doi.org/10.3386/w6691 
Russo, K. A. (2002). Effect (s) of traditional versus learning-style instructional strategies on the achievement and attitudes of first-year law students enrolled in legal research and writing course. St. John's University (New York), School of Education and Human Services.

Sadiq, S., \& Zamir, S. (2014). Effectiveness of modular approach in teaching at the university level. Journal of Education and Practice, 5, 103-109.

Sejpal, K. (2013). Modular method of teaching. International Journal for Research in Education Vol. 2,(2), Feb. 2013 (IRE) ISSN: 2320-091X.

Sewagegn, A. A., \& Diale, B. M. (2021). Modular/block teaching: Practices and challenges at higher education institutions of Ethiopia. Teaching in Higher Education, 26(6), 776-789. https://doi.org/10.1080/13562517.201 9.1681391

Torrefranca, E. C. (2017). Development and validation of instructional modules on rational expressions and variations. The Normal Lights, 11(1).

Tria, J. Z. (2020). The COVID-19 pandemic through the lens of education in the Philippines: The new normal. International Journal of Pedagogical Development and Lifelong Learning, 1(1), 2-4. https://doi.org/10.30935/ ijpdll/8311

Unay, Olga \& Esquierdo, Ida \& Calpa, May \& Basista, Danilo \& Pinca, Emilia \& Jr, Fel. (2016). Difficulties in College Algebra of Freshmen Students at the University of Eastern Philippines: Basis for Modular Construction. OALib. 03. 1-4. 10.4236/oalib.1102597.

Valencia, M. R. (2020, April). Modular approach in teaching science 10. International Journal of Trend in Scientific Research and Development (IJTSRD).

Wang, H. (2013). Academic Libraries in the US and China. Comparative Studies of Instruction, Government Documents, and Outreach Chandos Information Professional Series.

Weiss, C. C., Carolan, B. V., \& Baker-Smith, E. C. (2010). Big school, small school:(Re) testing assumptions about high school size, school engagement, and mathematics achievement. Journal of Youth and Adolescence, 39(2), 163-176. https://doi.org/10.1007/s10964-009-9402-3

Wilson, S. M., \& Peterson, P. L. (2006). Theories of learning and teaching: What do they mean for educators? (p. 2). Washington, DC: National Education Association.

World Bank (2020). How countries are using edtech (including online learning, radio, television, texting) to support access to remote learning during the COVID-19 pandemic. https://www.worldbank.org/en/topic/ edutech/brief/how-countries-are-using-edtech-to-support-remote-learning-during-the-covid-19-pandemic

Zhang, D. (2008). The effect of teacher education level, teaching experience, and teaching behaviors on student science achievement. Utah State University.

Zulueta, F., \& Guimbatan, K. (2002). Teaching Strategies and Educational Alternatives. Academic Publishing Corporation, Manila.

\section{Correspondence:}

ALLEN JAKE S. TALIMODAO*

allenjake.talimodao.ajt@gmail.com

https://orcid.org/0000-0003-4183-1233

DENNIS V. MADRIGAL

dennis_madrigal@yahoo.com

https://orcid.org/0000-0001-5548-2682

*Principal Correspondent 